\title{
REAÇÃO DE AMPLIFICAÇÃO ALEATÓRIA DE DNA POLIMÓRFICO A PARTIR DE AMOSTRAS DE ROBALO PEVA Centropomus parallelus
}

\author{
Random amplification polymorfic D N A from tissues of \\ Fat Snook Centropomus parallelus
}

\section{Kárita Cláudia Freitas ${ }^{1}$, Fabiano Bendhack², Sylvio Péllico N etto ${ }^{3}$, Humberto Maciel França Madeira ${ }^{4}$, Jane Eyre Gabriel ${ }^{5}$}

${ }^{1}$ Laboratório de Biologia Molecular A plicada àA gropecuária, Centro de Ciências A mbientais eA grárias, Pontifícia Universidade Católica do Paraná PUCPR. São José dos Pinhais, PR - Brasil.

${ }^{2}$ Centro de Propagação e Produção de O rganismos Marinhos CPPO M, Pontifícia Universidade Católica do Paraná PUCPR. Guaratuba, PR - Brasil.

${ }^{3}$ Centro de Ciências A mbientais eA grárias, Pontifícia Universidade Católica do Paraná PUCPR, São José dos Pinhais, PR - Brasil.

${ }^{4}$ Laboratório de Biologia Molecular A plicada àA gropecuária, Centro de Ciências A mbientais eA grárias, Pontifícia Universidade Católica do Paraná PUCPR São José dos Pinhais, PR - Brasil.

${ }^{5}$ Centro de Ciências Exatas e Sociais Aplicadas CCEA, Universidade Estadual da Paraíba UEPB. Patos, PB - Brasil, e-mail: eyre.gabriel@gmail.com

\begin{abstract}
Resumo
O marcador molecular RAPD vem sendo amplamente empregado em análises moleculares, proporcionando grandes avanços aos estudos de avaliação da estrutura genética entre populações de uma grande variedade de organismos. E ntretanto, determinadas limitações diretamente associadas à extração de D NA genômico e às condições de amplificação costumam restringir seu emprego. Nesse contexto, 0 presente estudo teve como objetivo estabelecer protocolos de otimização de reações de amplificação aleatória de D NA polimórfico a partir de amostras de tecidos isoladas de C entropomus parallelus a fim de assegurar maior reprodutibilidade e alto poder discriminatório dessa técnica. Um perfil eletroforético altamente variável foi detectado nas reações de amplificação aleatória do D NA genômico de robalo peva, sendo observados produtos amplificados com alta nitidez e tamanhos variando entre 100 a 3.000 pb. O s produtos de RAPD -PCR produziram um padrão de bandas altamente monomórfico, quando os primers AM13, O PW5 e O PA20 foram testados. Entretanto, consideráveis variações no tamanho e número de bandas amplificadas foram observadas apenas nas reações realizadas na presença do primer O PX 4. As descobertas apresentadas no presente estudo descrevem o estabelecimento de determinados procedimentos experimentais a fim de viabilizar os ensaios de amplificação arbitrária a partir de amostras de DNA genômico de robalo peva C . parallelus por análises de RAPD. Tais descobertas criam reais possibilidades para o uso da técnica de RAPD-PCR como ferramenta auxiliar nas análises de variabilidade e diversidade genética entre populações de robalo peva C . parallelus, possibilitando futuramente o desenvolvimento de diferentes trabalhos genético-moleculares empregando tal procedimento experimental.
\end{abstract}

Palavras-chave: RAPD-PCR; C entropomus parallelus; Robalo peva; O timização. 


\begin{abstract}
Random Amplified Polymorphic DNA (RAPD) markers are DNA fragments from PCR amplification of random segments of genomic DNA with single primer of arbitrary nucleotide sequence. Although this technique has some limitations, RAPD does not require any specific knowledge of the DNA sequence of the target organism unlike traditional PCR analysis. Within this context, the aim of the present study was to establish experimental procedure for the normalization of arbitrary amplification reactions from tissues isolated by fat snook Centropomus parallelus. Under these experimental conditions, a variable eletrophoretical profile was revealed in RAPD-PCR from genomic DNA samples of fat snook, whose amplified products had great clearness with molecular sizes ranging from 100 to 3,000 bp. RAPD-PCR products generated monomorphic DNA fragments, when the primers AM13, OPW5 and OPA20 were tested. Nevertheless, considerable variations in the size and number of amplified products were detected exclusively in reactions performed in the presence of primer OPX4. The results presented in this study describe the optimization of experimental procedure in order to normalize the steps involved in arbitrary amplification reactions from genomic DNA samples of fat snook. These findings create real possibilities for the use of RAPD-PCR as powerful tool in genetic variability and diversity between populations of fat snook C. parallelus, leading to further development of distinct molecular genetic analysis by using such experimental approach.
\end{abstract}

Keywords: RAPD-PCR; Centropomus parallelus; Fat snook; Optimization.

\section{INTRODUÇÃO}

Com 0 advento das técnicas empregando segmentos de D NA como marcadores moleculares, grandes avanços têm sido registrados nas últimas décadas no que se refere à identificação de espécies e híbridos; estabelecimento da filogenia da espécie e da população; determinação da estrutura populacional de uma espécie; identificação de linhagens; contribuição individual deumapopulação em um estoque que está sendo explorado; variação genética em populações selvagens e cultivadas; determinação do impacto genético da introdução de espécies cultivadas em populações naturais; determinação de estratégias de cruzamento para fins de criação e repovoamento; localização de marcadores associados a genes envolvidos com caracteres de interesse econômico (1).

Particularmente, os marcadores de polimorfismo deD NA amplificado ao acaso (RAPD , Random A mplified Polymorphic D N A ) são altamente eficazes na identificação de variações no DNA genômico entre subespécies ou populações devárias espécies; identificar linhagens distintas e determinar o impacto genético da introdução de espécies cultivadas em populações naturais (1). Segundo Hilsdorf et al. (2), análises de RAPD representam 0 segundo marcador mais empregado nos estudos anteriormente citados. Tal técnica consiste basicamente em uma variação do protocolo da reação em cadeia da polimerase, utilizando uma única pequena sequência de oligonucleotídios (primers), capazes de amplificar regiões arbitrárias do genoma $(3,4)$. D evido a seu fácil manuseio e reduzido número de etapas, é capaz de gerar resultados com certa rapidez em um curto período de tempo, a um baixo custo, comparado a outros marcadores. Além disso, não requer o conhecimento prévio do genoma em questão, emprega poucos nanogramas de DNA na presença de um número bem reduzido de reagentes e não exige instalações laboratoriais tão sofisticadas (3). Soma-se a todas essas vantagens, o fato que os marcadores RAPD asseguram a avaliação de um número elevado de genótipos em um curto prazo de tempo, além de sofrerem pouca influência ambiental (5).

Frente a esse cenário, o objetivo principal do presente estudo foi estabelecer ensaios experimentais paraaotimização das etapas envolvidas na extração de DNA genômico e nas reações de amplificação a partir de amostras de tecidos isoladas de robalo peva Centropomus parallelus por análises de RAPD, a fim de garantir maior reprodutibilidade e alto poder discriminatório dessa técnica. 


\section{MATERIAIS E MÉTODOS}

\section{Animais e colheita dos animais}

Vinte alevinos de robalo peva C entropomus parallelus, obtidos por reprodução induzida a partir de um pool de gametas sexuais oriundos de um único casal dereprodutores, foram empregados no presente estudo. Tais exemplares mantidos sob condições de cativeiro foram aleatoriamente colhidos de um mesmo reservatório instalado no Centro de Propagação e Produção de Organismos Marinhos CPPOM (2551'50.72"S / 48³3'52.99"W), localizado na cidade de Guaratuba (Estado do Paraná, Brasil). Imediatamente após a colheita, os animais foram estocados em etanol 95\% e armazenados a - $20^{\circ} \mathrm{C}$ para posterior análise.

\section{Extração de DNA genômico}

Amostras de DNA genômico foram isoladas a partir de $50 \mathrm{mg}$ de tecido muscular dorsal, como descrito por Wasko et al. (6). Tais tecidos foram incubados em $4 \mathrm{~mL}$ de tampão de digestão TNE S (10 mM Tris- $\mathrm{HCl}$ pH 8,0; $125 \mathrm{mM} \mathrm{NaCl} ; 10$ mM EDTA pH 8,0; 0,5\% SDS; 4 M ureia) na presença de $30 \mu \mathrm{L}$ de proteinase $\mathrm{K} 10 \mathrm{mg} / \mathrm{mL}$ (Invitrogen). Após agitação por aproximadamente 10 minutos em incubadora (Marconi, modelo MA420), a mistura foi mantida em banho-maria (Cientec, modelo GFRAN 400) a 37으, por 12 horas, para promover a total lise dos tecidos. Posteriormente, $4 \mathrm{~mL}$ de fenol:clorofórmio:álcool isoamílico (25:24:1) foram adicionados em cada tubo, seguida por vigorosa agitação por 15 minutos. Após centrifugação a $10.000 \mathrm{rpm}$ por 15 minutos (Beckman, modelo21R), aproximadamente $2 \mathrm{~mL}$ de fase aquosa foram precipitados em 0,1 volume de $\mathrm{NaCl} 1 \mathrm{M}$ e 0,6 volume de isopropanol absoluto. 0 precipitado de DNA genômico foi obtido por centrifugação a 10.000 rpm por 15 minutos, seguida por lavagem em $1 \mathrm{~mL}$ de etanol 70\%. As amostras de DNA foram secas à temperatura ambiente por 30 minutos e ressuspendidas em tampão TE (10 $\mathrm{mM}$ Tris-HCl pH 8,0; 1 mM EDTA pH 8,0) na presença de $1 \mu \mathrm{L}$ deRNAse $10 \mathrm{mg} / \mathrm{mL}$ (Invitrogen). A pósincubação a $37^{\circ} \mathrm{C}$ por 30 minutos, tais amostras foram estocadas a - $20^{\circ} \mathrm{C}$. A concentração das amostras de DNA foi estimada por leitura ao espectrofotômetro (BECKMAN, BU530), sendo sua integridade verificada em géis de agarose 1,0\% preparados com tampão TAE $1 \mathrm{X}$ concentrado (9 mM Tris-HCl pH 7,5; 9 mM ácido bórico; $1 \mathrm{mM}$ EDTA pH8,0), corados em solução de brometo de etídeo $0,5 \mu \mathrm{g} / \mathrm{mL}$ e fotografados com sistema digital KODAK EDAS 290.

\section{Reações de PCR-RAPD}

O padrão de polimorfismo molecular observado nos exemplares de robalo peva foi investigado por análises de RAPD -PCR, baseandose na amplificação de segmentos de D NA genômico a partir de quatro sequências oligonucleotídicas (OPW5 5'GGCGGATAAG 3', OPX 4 5'CCGCTACCGA3', OPA20 5'GTTGCGATCC3', AM13 5'CACGGCACAA3'). Dez ng de DNA genômico foram amplificados em tampão de PCR $1 X$ concentrado (20 mM Tris-Hcl, pH8,4, $50 \mathrm{mM}$ $\mathrm{KCl}), 4 \mathrm{mM}$ de $\mathrm{MgCl}_{2}, 0,7 \mathrm{mM}$ de mistura de dNTPs, $0,3 \mu \mathrm{M}$ primers e 1 unidade da enzima Taq DNA polimerase(Invitrogen).Ascondiçõesdeamplificação compreenderam desnaturação a $95^{\circ} \mathrm{C}$ por $30 \mathrm{~s}$, anelamento a $50^{\circ} \mathrm{C}$ por 1 min e extensão a $72^{\circ} \mathrm{C}$ por 5 min, totalizando 40 ciclos. Controles negativos foram incluídos em cada experimento, ondealíquotas da mistura de reação de PCR foram amplificadas na ausência de DNA genômico.

Os produtos de amplificação foram submetidos à eletroforese em gel de agarose 1,5\% fundidas em tampão TAE 1X concentrado $(40 \mathrm{mM}$ Tris- $\mathrm{HCl} \mathrm{pH} 7,5$, ácido acético 100\%, 1mM EDTA pH 8,0), corados em solução de brometo de etídeo $0,5 \mu \mathrm{g} / \mathrm{mL}$ e fotografados com sistema digital KODAK EDAS 290 para identificação e comparação das bandas amplificadas.

\section{RESULTADOS E DISCUSSÃO}

No presenteestudo, ensaios experimentais foram conduzidos a fim de otimizar as diferentes etapas envolvidas nos processos de extracão de DNA genômico e de amplificação por análises de RAPD a partir de amostras de tecidos isoladas de robalo peva $C$. parallelus.

Como observado na Figura 1, um perfil eletroforético altamente variável foi detectado nas reações de amplificação aleatória do DNA genômico de robalo peva, sendo observados produtos amplificados com alta nitidez e tamanhos variando entre 100 a $3.000 \mathrm{pb}$. Os produtos de 
RAPD-PCR produziram um padrão de bandas altamente monomórfico, quando os primers AM13, OPW5 e OPA20 foram testados (Figuras 1A, B e C). Entretanto, consideráveis variações no tamanho e número de bandas amplificadas foram observadas exclusivamente nas reações realizadas na presença do primer OPX 4 (Figura 1D).
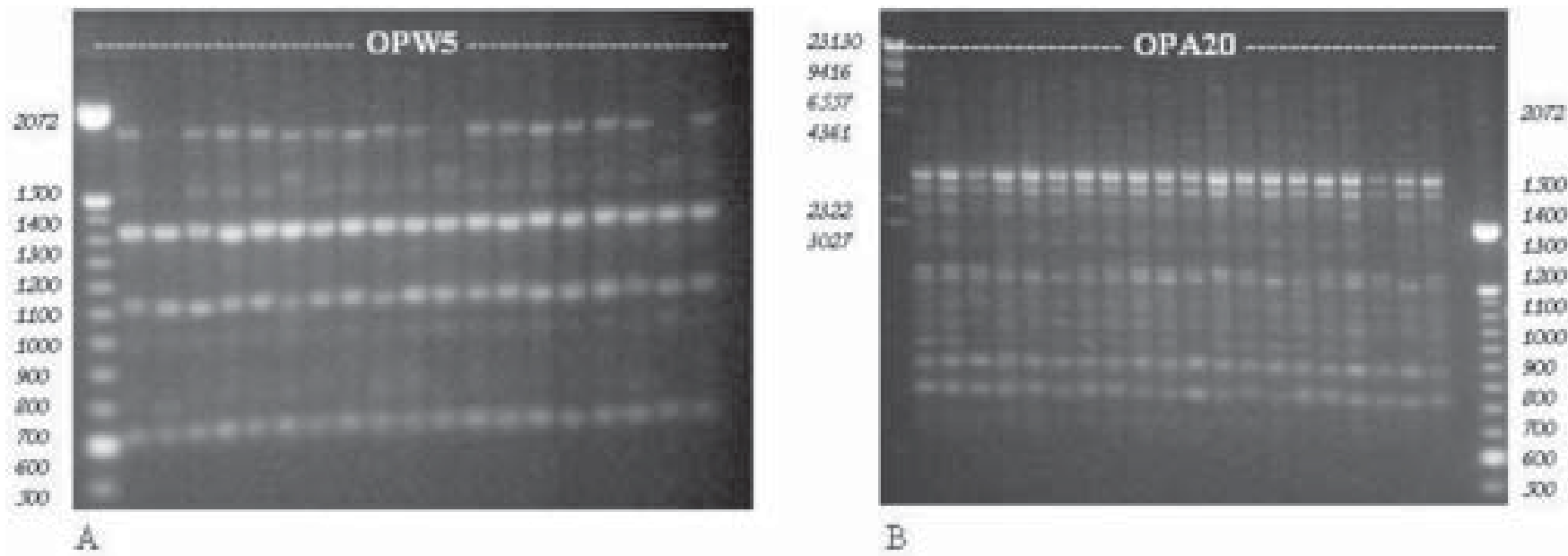

B
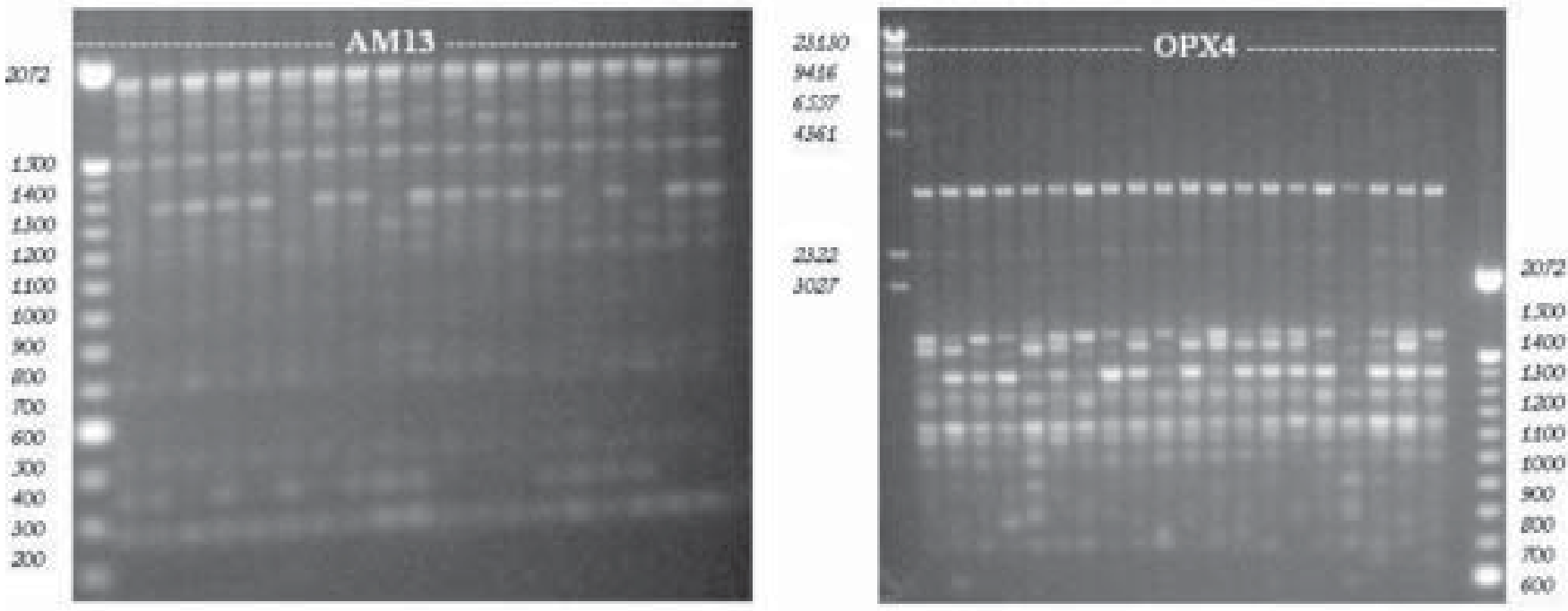

D

FIG URA 1 - Produtos de RSPD-PCR a partir de 10 ng de D NA genômico isolado de tecidos de robalo peva C entropomus parallelus na presença de distintas seqüências oligonucleotidicas. Primers OPW5 (A), O PA20 (B), AM 13 (C) e OPX 4 (D). Marcadores de peso molecular (Amersham Biosciences e Invitrogen)

É preciso ressaltar que, em tais condições, foi detectada a presença de distintas bandas específicas altamente definidas quanto ao tamanho e intensidade em todos os exemplares de robalo peva nas reações de amplificação empregando osdiferentesprimers testados (Figura1).Esses resultadoscaracterizam aamplificação defragmentosdeD NA quepoderiam serconsiderados "bandas marcadoras" para tal espécie. Em futuras etapas, novas estratégias experimentais poderão vir a empregar tais produtos de RAPD como instrumentos complementares nos estudos de identificação e discriminação molecular entre espécimes de robalo peva C. parallelus e demais organismos.

Embora sejam marcadas por certas limitações, as RAPD-PCRs não exigem 0 conhecimento prévio da sequência de D NA, uma vez que as variações genômicas detectadas por tal método baseiam-se na diferença entre indivíduos da distribuição dos sítios complementares a um primer curto (10 bases) de sequência aleatória (7). A 
partir de um único primer por reação, é possível verificar a geração de numerosos segmentos amplificados, cujas sequências são desconhecidas com tamanhos variáveis. Assim, assume-se que diferentes indivíduos produzem distintos padrões de fragmentos amplificados com base nas diferentes localizações dos sítios de hibridização dos primers ao longo da fita de DNA. Finalmente, as análises estatísticas são efetuadas baseando-se na distribuição, presença e ausência das bandas geradas pela reação de amplificação.

As descobertas apresentadas no presente estudo descrevem a otimização de determinados procedimentos experimentais a fim de viabilizar as reaçõesdeamplificação arbitráriasa partir deamostras de DNA genômico de robalo peva Centropomus parallelus por análises de RAPD. Vários relatos na literatura têm discorrido sobre as vantagens datécnica de RAPD -PCR como uma ferramenta poderosa nos estudos de caracterização da estrutura genética em uma grande variedade de populações de peixes $(8,9$, $10,11,12,13)$. Assim, novos primers deverão ser testados em ensaios adicionais de amplificação para a efetiva normalização de protocolos experimentais, favorecendo a detecção de perfis de amplificação altamente polimórficos. Particularmente, as análises de RAPD empregando amostras de robalo peva C. parallelus são de extrema importância aos programas de repovoamento da ictiofauna brasileira, uma vez que tal espécieé altamente atrativa devido à qualidade de sua carne, ao seu elevado valor comercial e sua grande importância para a subsistência de comunidades litorâneas. Futuramente, tais análises poderão fornecer novos subsídios para a utilização do marcadorRAPD nadiferenciação entrepopulações de C. parallelus, permitindo a avaliação da estrutura genética de populações cativas e selvagens de peixes. Nessas condições experimentais, a detecção de fragmentos de DNA em amostras de robalo peva reforça o uso potencial da técnica de RAPD-PCR na produção de dados de apoio, servindo de embasamento teórico-prático para as análises conduzidas em programas de repovoamento.

\section{AGRADECIMENTOS}

Os autores agradecem o apoio financeiro da Secretaria de Estado da Ciência, Tecnologia e Ensino Superior/ UnidadeG estora deFundo Paraná SETI/ UGF e daPrefeitura Municipal de G uaratuba (Estado do Paraná).

\section{REFERÊNCIAS}

1. Hilsdorf AWS, Krieger JE. Biologia molecular na conservação de peixes - ferramentas moleculares e conservação genética. Biotecnologia Ciência e D esenvolvimento. [O nline] 2005 [A cesso 2006 dez 12]. Disponível em: URL: http:// www.biotecnologia.com.br/ bio/ 5 j.htm

2. Hilsdorf AWS, Resende EK, Marques DKS. G enética e conservação de estoques pesqueiros de águas continentais no Brasil: situação atual e perspectivas. Embrapa Pantanal. [O nline] 2006 [A cesso $2006 \mathrm{dez}$ 12]. Disponível em: URL : http:/ / www.embrapa.br/ publicacoes/ online/ doc82

3. Ferreira ME, G rattapaglia D. Introdução ao uso de marcadores moleculares em análise genética. 3a ed. Brasília: Embrapa-Cenargen; 1998.

4. Leuzzi MSP, Pereira AC, Galhardo E, Foresti F, Moreira JA. Analysis by RAPD of the genetic structure of A styanax altiparanae (Pisces, Characiformes) in reservoirs on the Paranapanema River, Brazil. G enetics Molecular Biol. 2004; 27:355-62.

5. Costa MR, Cardoso ER, O haze MMM. Similaridade genética de cultivares de mandioca (M anihot esculenta) por meio de marcadores RAPD. Ciênc Agrotec. 2003;1:158-64.

6. Wasko AP, Martins C, Oliveira C, Foresti F. Non-destructive genetic in fish. an improved method for DNA extraction from fish and scales. Hereditas. 2003; 138:161-5.

7. Marques D KS. Caracterização genética do pirarucu Arapaima gigas (Cuvier) (Telesostei, O steoglossidae) da Bacia TocantinsAraguaia, Estado do Mato Grosso. [Tese] São Carlos: Universidade Federal de São Carlos UFSCar; 2003.

8. Callejas C, O chando MD. Phylogenetic relationships among Spanish Barbus species (Pisces, Cyprinidae) show by RAPD markers. Heredity. 2002;89:36-43.

9. D ergam JA, Paiva SR, Schaeffer CE , G odinho AL, Vieira F. Phylogeography and RAPD-PCR variation in $\mathrm{H}$ oplias malabaricus (Bloch, 1974) (Pisces, Teleostei) in southeastern Brazil. Genetics Molecular Biol. 2002;25:379-87. 
10.Prioli SMAP, Prioli AJ, Pavanelli CS, Júlio Jr $\mathrm{HF}$, Carraro D M, Carrer $\mathrm{H}$ et al. Identification of A styanax altipananae (Teleostei, Characidae) in the Iguaçu River, Brazil, based on mitochondrial DNA and RAPD markers. Genetics Molecular Biol. 2002;25:421-30.

11. Oliveira C, Pereira AC, Galhardo E, Foresti F, Moreira JA. Análise genética de populações selvagens de curimbatá (Prochilodus lineatus) e lambari (A styanax altiparanae) do rio Paranapanema, utilizando marcadores de RAPD. [Online] 2005 [Acesso $2006 \mathrm{dez}$ 12]. Disponível em: URL: http:/ / citenel.aneel.gov.br/ historico\%5CIcitenel\%5Ctrabalhos\%5C19.pdf

12.Povh JA, Moreira HLM, Ribeiro RP, Prioli AJ, Vargas L, Blanck DV, et al. Estimativa da variabilidade genética em linhagens de tilápia do Nilo (0 reochromis niloticus) com a técnica de RAPD. Animal Sci. 2005;27:1-10.

13.Lidani KCF, Lima JR, Torres RA, G abriel JE, Madeira HMF, Carneiro PCF. Variabilidade genética de um estoque cativo de jundiá (R hamdia quelen). Revista A cadêmica: Ciências Agrárias e Ambientais. 2006;4:47-56.

Recebido: 02/ 01/ 2007

R eceived: 01/ 02/ 2007

Aceito: 13/ 02/ 2007

A ccepted: 02/ 13/ 2007 